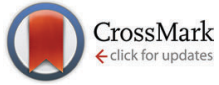

Cite this: Phys. Chem. Chem. Phys., $2014,16,21930$

Received 20th May 2014,

Accepted 27th August 2014

DOI: $10.1039 / c 4 c p 02188 f$

www.rsc.org/pccp

\section{SERS spectroscopic evidence for the integrity of surface-deposited self-assembled coordination cages $\dagger$}

\author{
Marina Frank, ${ }^{a}$ Sebastian Funke, ${ }^{b}$ Hainer Wackerbarth ${ }^{b}$ and Guido H. Clever ${ }^{\star a}$
}

\begin{abstract}
A series of self-assembled coordination cages $\left[\mathrm{Pd}_{4} \mathrm{~L}^{n}{ }_{8}\right]$ based on a phenothiazine backbone has been investigated by means of Raman spectroscopy in solution and by Surface Enhanced Raman Scattering (SERS) on a nanostructured Au surface. The experiments demonstrate that the cages can be clearly distinguished from their constituting ligands by their Raman spectroscopic signatures. Furthermore, the structural integrity of the interpenetrated coordination cages upon deposition on the Au surface was demonstrated for the first time. The signal assignment of the experimental vibrational spectra was supported by Density Functional Theory (DFT) calculations on suitable molecular models.
\end{abstract}

The study of self-assembled coordination cages ${ }^{1}$ is gaining in interest because of their potential for application in selective guest binding, ${ }^{2}$ stabilization of reactive compounds, ${ }^{3}$ catalysis ${ }^{4}$ and the synthesis of redoxactive ${ }^{5}$ and light-switchable materials. ${ }^{6}$ Although self-assembled systems are routinely studied in solution or as bulk materials, the examination of surface-confined supramolecular structures has become a popular alternative. ${ }^{7}$

Phenothiazine and its derivatives have been widely investigated because of their attractive properties in pharmacology ${ }^{8}$ and their use in charge separation devices. ${ }^{9}$

Applications in the latter field are based on their good electron donor abilities. For example, phenothiazine derivatives have been used as surface-mounted photosensitizers on semiconducting supports in dye-sensitized and organic polymer solar cells. ${ }^{10}$ Traditionally, these applications make use of discrete organic building blocks or covalent polymers. When self-assemblies are considered to be used in such a context, however, the surface stability of the supramolecules becomes an important question.

In the present paper we show a detailed experimental study by means of Raman spectroscopy in solution and on nanostructured

\footnotetext{
${ }^{a}$ Institute of Inorganic Chemistry, Georg-August University Göttingen, Tammannstr. 4, 37077 Göttingen, Germany. E-mail: gclever@gwdg.de; Web: www.clever-lab.de

${ }^{b}$ Photonic Sensor Technology, Laser-Laboratorium Göttingen e.V.,

Hans-Adolf-Krebs-Weg 1, 37077 Göttingen, Germany

† Electronic supplementary information (ESI) available: Further Raman, SERS and calculated spectra. See DOI: 10.1039/c4cp02188f
}

$\mathrm{Au}$ surfaces for a series of recently reported self-assembled coordination cages $\left[\mathrm{Pd}_{4} \mathbf{L}^{1-3}{ }_{8}\right] \cdot{ }^{11}$ These closely related interpenetrated double cages contain eight bis-monodentate ligands $\mathbf{L}^{1-3}$, which are based on the heterocycle phenothiazine and differ in their oxygenation state at the central sulfur atom. In total, four square-planar coordinated $\mathrm{Pd}(\mathrm{II})$ metal ions are coordinated by these ligands (Fig. 1a). As we showed before, these double cages are capable of binding small guest molecules such as $\mathrm{BF}_{4}{ }^{-}$and halide anions in their three pockets. ${ }^{12}$ In addition, we showed that S-oxidation of the cages can be achieved, both, in solution or in the solid state by the action of oxidants such as $\mathrm{Fe}(\mathrm{III})$ or $\mathrm{Cu}$ (II) salts, organic peroxides or molecular oxygen. ${ }^{11}$

Surface Enhanced Raman Scattering (SERS) is an invaluable and straightforward technique to approach the question of surface stability of supramolecular structures. SERS allows to overcome some limitations of conventional Raman spectroscopy. ${ }^{13}$ The enhancement of the signal intensity can be attributed to two effects: an increase in the electromagnetic field intensity near the metal surface induced by the resonant excitation of the surface plasmons of the nanostructured metal and/or a chemical effect induced by a modulation of the electronic polarizability of the bound molecule. In the first case the enhancement is not dependent on the specific interactions between the molecule and the metal, but is strongly related to the characteristics of the metal surface. The contribution from the electromagnetic enhancement can be up to ten orders of magnitude while the chemical enhancement is between 10 and $100 .{ }^{14}$ Furthermore, redox-driven and electric field induced structural changes on metallic surfaces can be directly monitored by SERS under electrochemical control. ${ }^{15}$

In the context of macrocyclic and self-assembled supramolecular structures, SERS methods have been used only scarcely so far. ${ }^{16}$ In order to examine the surface stability of the interpenetrated coordination cages we have compared their vibrational spectra after deposition on a gold surface by using SERS with the ones in solution by using Raman spectroscopy. Care was taken that the characteristic bands of the ligands and the cages are not overlapped by solvent bands, therefore the solution measurements 
a)

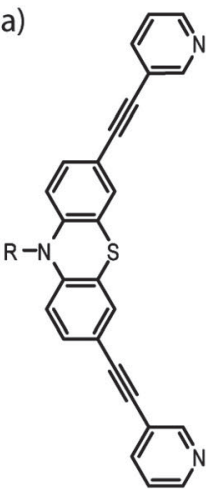

$\mathbf{L}^{1}$

8

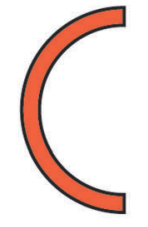

$\mathbf{L}^{\mathrm{n}}$

b)

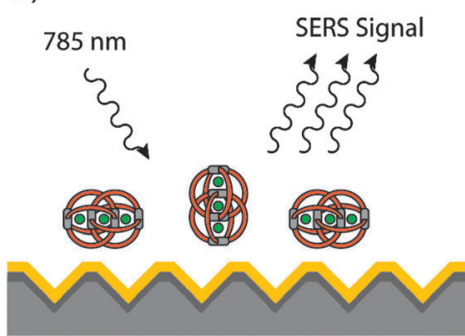

Fig. 1 (a) Investigated ligands $\mathbf{L}^{n}$ and their corresponding self-assembled double cages $\left[3 \mathrm{BF}_{4}\left(\mathrm{aPd}_{4} \mathrm{~L}_{8}{ }_{8}\right]\left(\mathrm{BF}_{4}\right)_{5}\right.$ with $n=1-3\left(\mathrm{R}=\right.$ hexyl; not all $\mathrm{BF}_{4}$ counter anions are shown). (b) Schematic representation of the SERS (Surface Enhanced Raman Scattering) experimental setup. The size of the double cages (length $2.5-2.6 \mathrm{~nm}$ ) is exaggerated compared to the size of the nanoscopic surface features $(1.4 \times 1.4 \mu \mathrm{m})$ of the metal substrate.

were carried out in two solvents (acetonitrile and acetone, see Fig. S1 in the ESI $\dagger$ ). The SERS measurements were carried out using Au coated nanostructured silicon chips. The analytes were deposited as acetonitrile solutions on the surface and the solvent was allowed to evaporate yielding a thin film (Fig. 1b). The complete evaporation of the solvent was indicated by the lack of any acetonitrile bands in the SERS spectra. The plasmonic effect of the nanostructured surface was verified by a comparison with a planar Au surface (see Fig. S2 in the ESI†). Density functional theory (DFT) computations were employed to achieve a partial assignment of the experimentally obtained vibrations for the electronic ground state of the examined molecules.

Interestingly, a comparison of the double cage spectra with the spectra of their constituting ligands reveals a significant difference not only in the intensity distribution of the vibrational bands, but also in the frequencies of some characteristic signals. For example, the vibrational bands in the normal Raman spectrum of $\left[3 \mathrm{BF}_{4} @ \mathrm{Pd}_{4} \mathbf{L}_{8}^{1}\right]\left(\mathrm{BF}_{4}\right)_{5}$ at $2210 \mathrm{~cm}^{-1}, 1163 \mathrm{~cm}^{-1}$ and

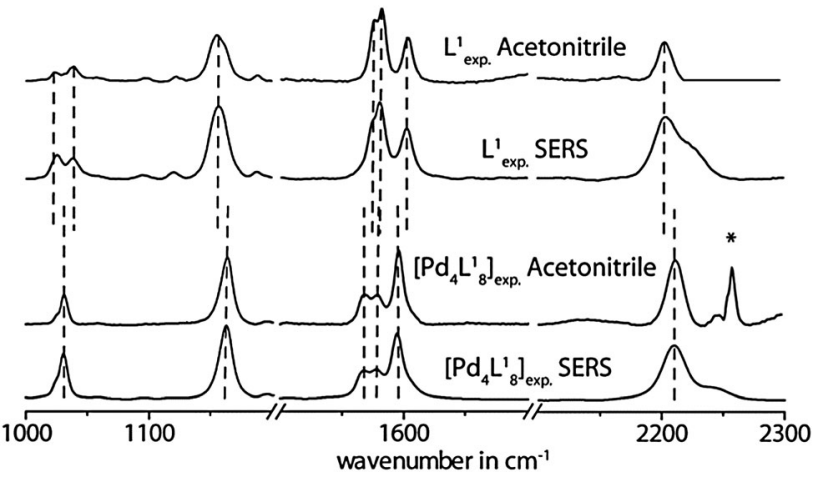

Fig. 2 Comparison of experimental Raman spectra measured in solution (acetonitrile) and on the Au surface for the free ligand $\mathbf{L}^{1}$ and the double cage $\left[3 \mathrm{BF}_{4}\left(\mathrm{aPd}_{4} \mathrm{~L}_{8}^{1}\right]\left(\mathrm{BF}_{4}\right)_{5} .{ }^{*}\right.$ Artefact.

$1031 \mathrm{~cm}^{-1}$ are shifted to higher wavenumbers by $\Delta \omega$ $\sim$ 6-9 $\mathrm{cm}^{-1}$ with respect to the free ligand $\mathbf{L}^{1}$ (see Fig. 2). In contrast, the three intense Raman bands at $1568 \mathrm{~cm}^{-1}$, $1578 \mathrm{~cm}^{-1}$ and $1595 \mathrm{~cm}^{-1}$ are displaced to lower wavelengths by $2-8 \mathrm{~cm}^{-1}$. Since these significant differences between the ligand and cage spectra are conserved in the results of the SERS measurements, we conclude that the supramolecular assemblies do not decompose/disassemble on the Au surface under release of the free ligands. Similar results have been obtained for the oxygenated ligand derivatives $\mathbf{L}^{2}$ and $\mathbf{L}^{3}$ and their corresponding double cages (see Fig. 3 and the ESI $\dagger$ ). The frequency shifts in the spectra of double cage $\left[3 \mathrm{BF}_{4} @ \mathrm{Pd}_{4} \mathbf{L}_{8}^{3}\right]\left(\mathrm{BF}_{4}\right)_{5}$ are rather small compared to the free ligand $\mathbf{L}^{3}$. Still, the cage spectrum can be unambiguously differentiated from the ligand spectrum.

In principal, the SERS effect can cause a shift in the Raman frequencies. This is usually the case if strong interactions between a non-bonding orbital of the molecules and the surface are present. Then even new bands can appear due the formation of charge transfer complexes and the chemical enhancement can be observed. In the absence of such effects the frequencies of the bands in the SERS spectrum are hardly shifted with respect to the Raman spectrum in solution. ${ }^{17}$

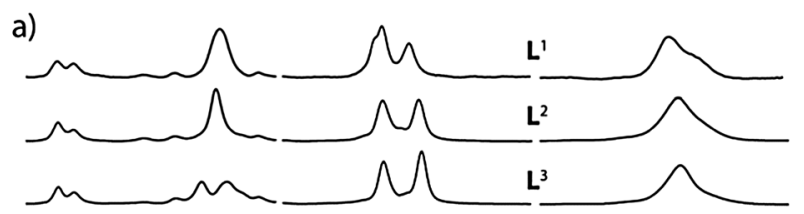

b)

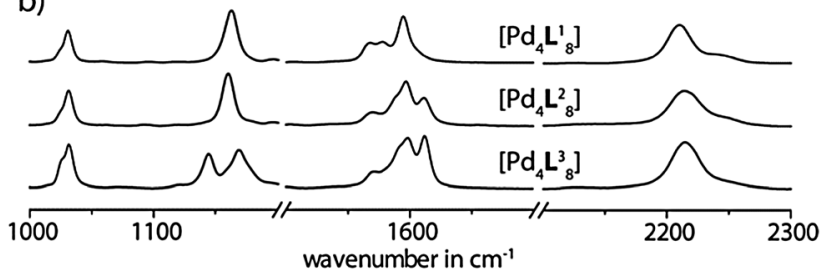

Fig. 3 Comparison of experimental SERS spectra for (a) free ligands $\mathrm{L}^{n}$ $(n=1-3)$ and (b) corresponding double cages $\left[3 \mathrm{BF}_{4}\left(\mathrm{aPd}_{4} \mathrm{~L}_{8}{ }_{8}\right]\left(\mathrm{BF}_{4}\right)_{5}\right.$. 
Moreover, the comparison of the band intensities of Raman and SERS spectra provide information about the orientation of molecules on the surface. Modes involving changes in molecular polarizability with a component normal to the surface are the most enhanced. The herein observed similarities of the spectral parameters of the solid analyte (ligand or cage), the analyte in solution and the analyte adsorbed on the nanostructured $\mathrm{Au}$ surface indicate weak intermolecular interactions and weak interactions between the analyte and the surface (see Fig. S3 and S4 in the ESI $\dagger$ ). Weak interactions between the molecules and the surface are not expected to lead to specific orientations of the adsorbed molecules. This assumption agrees quite well with the fact that even the intensity distribution of the bands of the Raman and SERS spectrum of the cages (ligands) are almost identical, as the similar intensity distribution of the bands points toward a random orientation of the cages (ligands) on the surface as it is illustrated in Fig. 1b.

Although a comparison of the ligand spectra among each others shows a substantial similarity in the intensity distribution patterns of the most prominent bands, some of the signals appear at significantly different frequencies. For example, the band at $2203 \mathrm{~cm}^{-1}$ in the normal Raman spectrum of $\mathbf{L}^{1}$ shifts to $2209 \mathrm{~cm}^{-1}$ for $\mathbf{L}^{2}$ and up to $2216 \mathrm{~cm}^{-1}$ for $\mathbf{L}^{3}$. The resonance around $1142 \mathrm{~cm}^{-1}$ is split in to two signals for the dioxygenated derivative $\mathbf{L}^{3}$, which is not the case for the other ligands. Likewise, the spectra of the cages are distinguishable. In particular, the band assigned to the alkyne group vibration is shifted from $2210 \mathrm{~cm}^{-1}$ for $\left[3 \mathrm{BF}_{4} @ \mathrm{Pd}_{4} \mathbf{L}_{8}{ }_{8}\right]\left(\mathrm{BF}_{4}\right)_{5}$ over $2214 \mathrm{~cm}^{-1}$ for $\left[3 \mathrm{BF}_{4} @ \mathrm{Pd}_{4} \mathbf{L}_{8}^{2}\right]\left(\mathrm{BF}_{4}\right)_{5}$ up to $2215 \mathrm{~cm}^{-1}$ for $\left[3 \mathrm{BF}_{4} @ \mathrm{Pd}_{4} \mathbf{L}_{8}^{3}\right]\left(\mathrm{BF}_{4}\right)_{5}$ in the normal Raman spectrum. As in the case of the ligand $\mathbf{L}^{3}$, the double cage $\left[3 \mathrm{BF}_{4} @ \mathrm{Pd}_{4} \mathbf{L}_{8}^{3}\right]\left(\mathrm{BF}_{4}\right)_{5}$ shows an additional band at $1145 \mathrm{~cm}^{-1}$. Moreover, the distinction between the cages is obvious for the Raman bands around $1600 \mathrm{~cm}^{-1}$. In this area, three bands appear for all three cages. In the case of $\left[3 \mathrm{BF}_{4} @ \mathrm{Pd}_{4} \mathbf{L}_{8}^{1}\right]\left(\mathrm{BF}_{4}\right)_{5}$ these bands are shifted to lower wavenumbers, while the bands for the oxygenated derivatives come at higher wavenumbers. The oxygenated double cages can be distinguished by the intensity pattern of the bands around $1600 \mathrm{~cm}^{-1}$.

For the assignment of the vibrational bands (see Fig. S7-S9 in the ESI $\dagger$ ), the spectra were calculated by DFT methods on the B3LYP/ $6-31 \mathrm{G}^{*}$ level of theory as implemented in Gaussian $09{ }^{18}$ Fig. 4 compares the experimental SERS spectra of the ligands $\mathbf{L}^{1-3}$ with the results from the calculations. Due to a systematic overestimation of the vibrational frequencies by the used computational method, the calculated spectra had to be corrected by using an appropriate scaling factor or a scaling equation. For this reason, some scaling methods have been tested, such as scaling with a functional- and basis-set-specific constant factor $\left(0.9614 \times \omega_{\text {calc }}=\omega_{\text {corr }}\right),{ }^{19}$ a reported scaling equation for phenothiazines $\left(0.9519 \times \omega_{\text {calc }}+23.3=\omega_{\text {corr }}\right)^{20}$ and a self-developed scaling equation $\left(0.9377 \times \omega_{\text {calc }}+45.2=\omega_{\text {corr }}\right)$, which gave the best fit. Although the first two scaling approaches predicted the frequencies for the signals in the middle parts of the spectra quite well, in the ranges with smaller and larger wavenumbers, however, the deviation of the shifts from the experimental values was more pronounced. The best correlation was achieved by
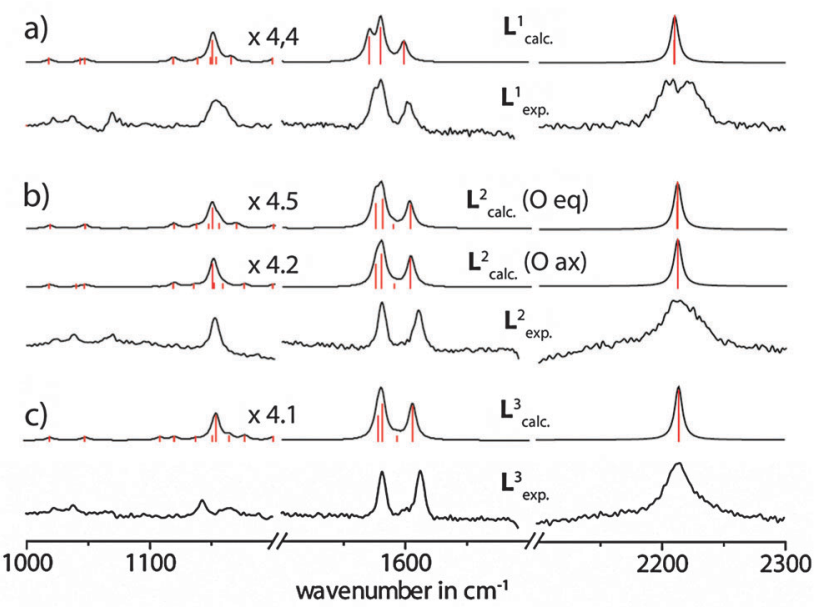

Fig. 4 Comparison of the experimental Raman spectra in solution (acetone) and the calculated vibrational Raman spectra for the free ligands (a) $\mathbf{L}^{1}$, (b) $\mathbf{L}^{2}$ and $(c) L^{3}$. Calculated spectra were subjected to a gaussian peak broadening of $4 \mathrm{~cm}^{-1}$. The intensities of the calculated spectra below $1800 \mathrm{~cm}^{-1}$ were scaled by the factors printed in the figure.

applying the self-derived linear scaling equation and this was finally used for the uniform scaling of all further calculated values. The obtained errors for the most intensive bands were less than $1 \%$ compared to the experimental spectra (see Table 1). The intensity patterns were satisfyingly reflected by the calculation method, although the intensities of the bands around $2200-2220 \mathrm{~cm}^{-1}$ were overestimated by the calculations.

Fig. 5 shows the assignment of the most prominent signals in the spectrum of ligand $\mathbf{L}^{1}$ to the calculated vibrational modes. Obviously, the stretching band of the alkyne linkers is degenerated and is represented by two frequencies at 2209.0 and $2209.4 \mathrm{~cm}^{-1}$. Due to line broadening effects only one signal is observed in the experimental spectra. The next three less intensive bands are found at $1597.9 \mathrm{~cm}^{-1}, 1569.9 \mathrm{~cm}^{-1}$ and $1150.0 \mathrm{~cm}^{-1}$. These modes consist of group vibrations comprising predominantly the phenothiazine backbone or the pyridine units which is in good agreement with literature reported data for phenothiazine and ethynylpyridine derivatives. ${ }^{21}$ Similar vibrational modes were obtained in the calculations of the oxygenated ligand derivatives $\mathbf{L}^{2}$ and $\mathbf{L}^{3}$ (see the ESI $\dagger$ ). The sulfoxide stretching bands were predicted to be found at $1034 \mathrm{~cm}^{-1}$ and $1060 \mathrm{~cm}^{-1}$ for the axial isomer of ligand $\mathbf{L}^{2}$ and $1038 \mathrm{~cm}^{-1}$ and $1069 \mathrm{~cm}^{-1}$ for the equatorial isomer with respect to the position of the oxygen substituent. The question arose whether the $\mathrm{S}=\mathrm{O}$ vibrations alone can be used for the unambiguous discrimination between the three ligand (or cage) isomers? Unfortunately, the $S=O$ stretching resonances of $\mathbf{L}^{2}$ are a part of group vibrations together with numerous backbone deformations. For ligand $\mathbf{L}^{3}$, the most prominent sulfoxide vibrations were found at $1046 \mathrm{~cm}^{-1}$ and $1254 \mathrm{~cm}^{-1}$. This is in good agreement with the reported vibrational bands for other oxygenated phenothiazine derivatives. ${ }^{22}$ Nevertheless, all sulfoxide vibrations are of very low intensity and therefore not very well suited to serve as characteristic and outstanding markers of the ligand systems. Therefore, the assignment of the samples to the ligands and cages in their different oxidation states was rather based on a 


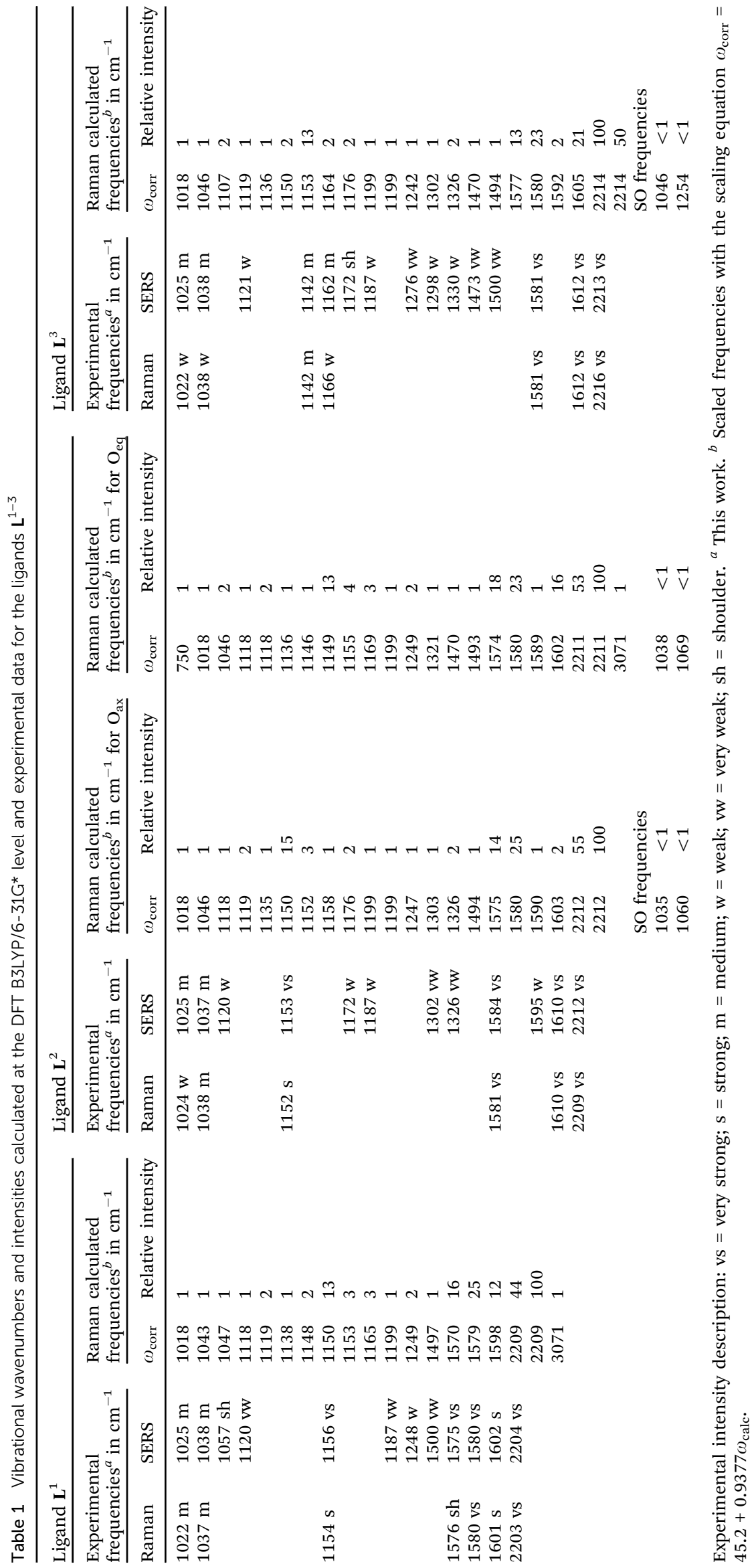



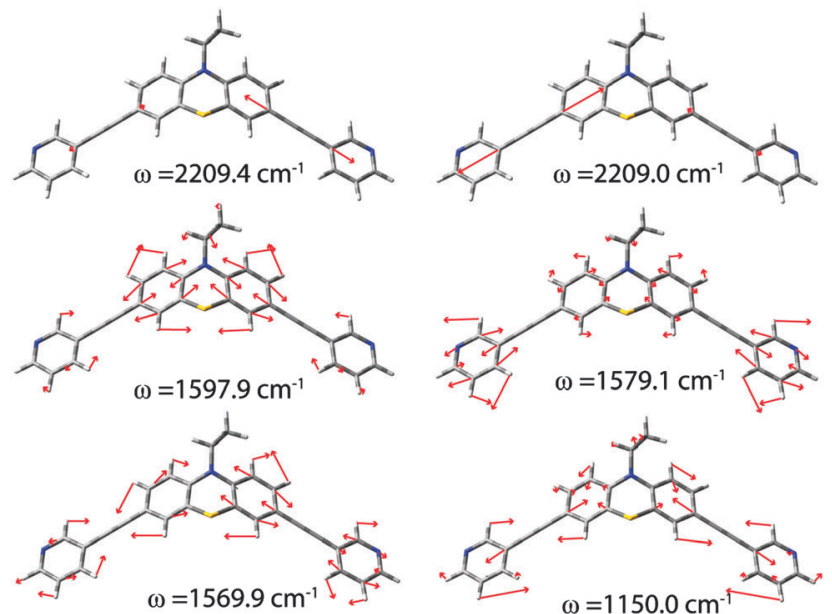

Fig. 5 Calculated vibrational modes with the highest intensities for ligand $\mathbf{L}^{1}$

comprehensive comparison of the spectral features in the range between $\sim 1000$ and $2300 \mathrm{~cm}^{-1}$ as described above.

\section{Materials and experimental setup}

\section{Calculations}

Density functional theory (DFT) calculations were performed using the Gaussian '09 program with the Becke 3-Parameter Lee-Yang-Parr correlation functional (B3LYP) and the 6-31G* split-valence polarization basis set. No imaginary frequencies were observed for the optimized structures. The applied scaling equation for correcting the computed vibrational frequencies was found empirically. In order to save computation time the hexyl residues were truncated and replaced by ethyl groups.

\section{Raman spectroscopy}

The Raman and SERS spectra were collected with a standard system (Kaiser Optical System Inc., Ann Arbor, MI, USA); the $785 \mathrm{~nm}$ (line width $0.06 \mathrm{~nm}$ ) GaAlAs diode laser (Invictus, Kaiser Optical Systems, Inc.) light was focused onto the sample. The incident power of the laser emission was $c a .50 \mathrm{~mW}$ at the probe head by a recording time of 10 and $5 \mathrm{~s}$ with 1 and 20 accumulations for SERS and Raman experiments, respectively. The diffracted light was recorded with a CCD camera (iDus, Andor Technology plc.) The spectral resolution was $5 \mathrm{~cm}^{-1}$. The most important prerequisite when comparing Raman shifts is the reproducibility (or repeatability) of the experiment. Kaiser Optical Systems provide a Raman shift tolerance between \pm 0.5 and $\pm 1.0 \mathrm{~cm}^{-1}$. Individual system performance will not vary to this extent. Upon calibration, a system should yield Raman shift values repeatable to $\pm 0.1 \mathrm{~cm}^{-1}$.

For the normal Raman measurements the concentration was $2.80 \mathrm{~mm}$ for the ligand and $0.35 \mathrm{~mm}$ for the double cage. The normal Raman spectra have been corrected by subtraction of the solvent bands. Two different solvents (acetonitrile and acetone) were employed to check for overlapping bands in various regions of the spectra. Due to subtraction artefacts only regions with no significant overlap with the solvent bands are depicted and discussed here. For the full spectra and the overlapping regions of the solvents and the analytes see ESI. $\dagger$ In the case of the SERS measurements $1 \mu \mathrm{L}$ of the solutions were used to coat the $\mathrm{Au}$ substrate. The solvent was let to evaporate before the measurements.

All SERS spectra were recorded on a commercially available nanostructured gold surface (Klarite, Renishaw Diagnostics Ltd). This SERS substrate consists of gold-coated periodic square lattice of inverted pyramid pits $(\sim 1.5 \mu \mathrm{m}$ wide and $\sim 1 \mu \mathrm{m}$ deep). ${ }^{17 a, 23}$

Due to the background signal, the Raman and surface enhanced Raman spectra have to be corrected by a baseline correction. We have developed an algorithm for baseline correction by connecting cubic splines. ${ }^{24}$

\section{Conclusions}

In this paper we could show that a series of self-assembled, redox-active double cages remains structurally stable upon adsorption on an Au surface. This observation will be helpful for building devices such as flow sensors or organic electronic circuits based on surface-confined functional supramolecular systems. Both, the previously reported host-guest chemistry and the unique electrochemical features of our interpenetrated cages promise to serve as exploitable functionalities in this context. We could show that it is possible to differentiate between the free ligands and the ligands embedded in the supramolecular structures by means of Raman and SERS spectroscopy. In addition, we could demonstrate that vibrational spectroscopy allows for an unambiguous differentiation of the species even within the series of the three structurally very similar cage structures that only differ by the oxygenation state of the ligand's sulfur atoms.

\section{Acknowledgements}

M.F. thanks the Evonik Foundation for a PhD fellowship. We thank the DFG (CL 489/2-1) and the Fonds der Chemischen Industrie for generous financial support.

\section{Notes and references}

1 (a) M. D. Pluth and K. N. Raymond, Chem. Soc. Rev., 2007, 36, 161; (b) S. J. Dalgarno, N. P. Power and J. L. Atwood, Coord. Chem. Rev., 2008, 252, 825; (c) D. J. Tranchemontagne, Z. Ni, M. O'Keeffe and O. M. Yaghi, Angew. Chem., Int. Ed., 2008, 47, 5136; (d) R. Chakrabarty, P. S. Mukherjee and P. J. Stang, Chem. Rev., 2011, 111, 6810; (e) T. K. Ronson, S. Zarra, S. P. Black and J. R. Nitschke, Chem. Commun., 2013, 49, 2476.

2 (a) N. Gimeno and R. Vilar, Coord. Chem. Rev., 2006, 250, 3161; (b) J. L. Sessler, P. Gale, W.-S. Cho and S. J. Rowan, Anion Receptor Chemistry, Monographs in Supramolecular Chemistry, Royal Society of Chemistry, Cambridge, 2006; (c) S. O. Kang, J. M. Llinares, V. W. Day and K. Bowman-James, Chem. Soc. Rev., 2010, 39, 3980; (d) S. Freye, J. Hey, A. Torras-Galán, D. Stalke, R. Herbst-Irmer, M. John and G. H. Clever, Angew. 
Chem., Int. Ed., 2012, 51, 2191; (e) S. Freye, D. M. Engelhard, M. John and G. H. Clever, Chem. - Eur. J., 2013, 19, 2114; $(f)$ J. M. Dieterich, G. H. Clever and R. A. Mata, Phys. Chem. Chem. Phys., 2012, 14, 12746.

3 (a) P. Mal, B. Breiner, K. Rissanen and J. R. Nitschke, Science, 2009, 324, 1697; (b) D. Fiedler, R. G. Bergman and K. N. Raymond, Angew. Chem., Int. Ed., 2006, 45, 745; (c) M. Kawano, Y. Kobayashi, T. Ozeki and M. Fujita, J. Am. Chem. Soc., 2006, 128, 6558.

4 (a) M. Yoshizawa, J. K. Klosterman and M. Fujita, Angew. Chem., Int. Ed., 2009, 48, 3418; (b) in Molecular Encapsulation: Organic Reactions in Constrained Systems, ed. U. H. Brinker and J. MieussetWiley, Hoboken, 2010.

5 S. Bivaud, J.-Y. Balandier, M. Chas, M. Allain, S. Goeb and M. Sallé, J. Am. Chem. Soc., 2012, 134, 11968.

6 M. Han, R. Michel, B. He, Y.-S. Chen, D. Stalke, M. John and G. H. Clever, Angew. Chem., Int. Ed., 2013, 52, 1319.

7 (a) E. Menozzi, R. Pinalli, E. A. Speets, B. J. Ravoo, E. Dalcanale and D. N. Reinhoudt, Chem. - Eur. J., 2004, 10, 2199; (b) T. D. Nguyen, H. R. Tseng, P. C. Celestre, A. H. Flood, Y. Liu, J. F. Stoddart and J. I. Zink, Proc. Natl. Acad. Sci. U. S. A., 2005, 102, 10029; (c) T. Kudernac, S. Lei, J. A. A. W. Elemans and S. De Feyter, Chem. Soc. Rev., 2009, 38, 402; (d) N. Miyashita and D. G. Kurth, J. Mater. Chem., 2008, 18, 2636; (e) A. G. Slater, P. H. Beton and N. R. Champness, Chem. Sci., 2011, 2, 1440.

8 M. J. Ohlow and B. Moosmann, Drug Discovery Today, 2011, 16, 119.

9 (a) D. G. McCafferty, D. A. Friesen, E. Danielson, C. G. Wall, M. J. Saderholm, B. W. Erickson and T. J. Meyer, Proc. Natl. Acad. Sci. U. S. A., 1996, 93, 8200; (b) M. Borgström, O. Johansson, R. Lomoth, H. B. Baudin, S. Wallin, L. Sun, B. Akermark and L. Hammarström, Inorg. Chem., 2003, 42, 5173; (c) E. A. Weiss, M. J. Ahrens, L. E. Sinks, A. V. Gusev, M. A. Ratner and M. R. Wasielewski, J. Am. Chem. Soc., 2004, 126, 5577; (d) H. Tian, X. Yang, R. Chen, Y. Pan, L. Li, A. Hagfeldt and L. Sun, Chem. Commun., 2007, 3741; (e) K. Kawai, Y. Osakada, M. Fujitsuka and T. Majima, J. Phys. Chem. B, 2008, 112, 2144; $(f)$ M. Marszalek, S. Nagane, A. Ichake, R. Humphry-Baker, V. Paul, S. M. Zakeeruddin and M. Grätzel, J. Mater. Chem., 2011, 22, 889; (g) P. K. Poddutoori, A. S. D. Sandanayaka, N. Zarrabi, T. Hasobe, O. Ito and A. van der Est, J. Phys. Chem. A, 2011, 115, 709; (h) S. Bay, T. Villnow, G. Ryseck, V. Rai-Constapel, P. Gilch and T. J. J. Müller, ChemPlusChem, 2013, 78, 137.

10 (a) R. Argazzi, C. A. Bignozzi, T. A. Heimer, F. N. Castellano and G. J. Meyer, J. Am. Chem. Soc., 1995, 117, 11815; (b) H. Tian, X. Yang, R. Chen, Y. Pan, L. Li, A. Hagfeldt and L. Sun, Chem. Commun., 2007, 3741; (c) G. Sang, Y. Zou and Y. Li, J. Phys. Chem. C, 2008, 112, 12058; (d) P. Rajakumar, C. Satheeshkumar, M. Ravivarma, S. Ganesan and P. Maruthamuthu, J. Mater. Chem. A, 2013, 1, 13941.

11 M. Frank, J. Hey, I. Balcioglu, Y.-S. Chen, D. Stalke, T. Suenobu, S. Fukuzumi, H. Frauendorf and G. H. Clever, Angew. Chem., Int. Ed., 2013, 52, 10102.

12 M. Frank, J. M. Dieterich, S. Freye, R. A. Mata and G. H. Clever, Dalton Trans., 2013, 42, 15906.
13 For reviews see: (a) K. Kneipp, H. Kneipp, I. Itzkan, R. R. Dasari and M. S. Feld, J. Phys.: Condens. Matter, 2003, 14, R597-R624; (b) M. Moskovits, J. Raman Spectrosc., 2005, 36, 485; (c) W. E. Smith, Chem. Soc. Rev., 2008, 37, 955; (d) L. Guerrini and D. Graham, Chem. Soc. Rev., 2012, 41, 7085.

14 (a) P. L. Stiles, J. A. Dieringer, N. C. Shah and R. P. Van Duyne, Annu. Rev. Anal. Chem., 2008, 1, 60; (b) S. Schlücker, Angew. Chem., Int. Ed., 2014, 53, 4756.

15 (a) H. Wackerbarth and P. Hildebrandt, ChemPhysChem, 2003, 4, 714; (b) H. Wackerbarth, U. Klar, W. Günther and P. Hildebrandt, Appl. Spectrosc., 1999, 53, 283.

16 (a) A. McNally, R. J. Forster and T. E. Keyes, Phys. Chem. Chem. Phys., 2009, 11, 848; (b) S. Mahajan, T.-C. Lee, F. Biedermann, J. T. Hugall, J. J. Baumberg and O. A. Scherman, Phys. Chem. Chem. Phys., 2010, 12, 10429; (c) E. H. Witlicki, C. Johnsen, S. W. Hansen, D. W. Silverstein, V. J. Bottomley, J. O. Jeppesen, E. W. Wong, L. Jensen and A. H. Flood, J. Am. Chem. Soc., 2011, 133, 7288.

17 (a) H. Wackerbarth, C. Salb, L. Gundrum, M. Niederkrüger, K. Christou, V. Beushausen and W. Viöl, Appl. Opt., 2010, 49, 4362; (b) H. Wackerbarth, L. Gundrum, C. Salb, K. Christou and W. Viöl, Appl. Opt., 2010, 49, 4367.

18 M. J. Frisch, G. W. Trucks, H. B. Schlegel, G. E. Scuseria, M. A. Robb, J. R. Cheeseman, G. Scalmani, V. Barone, B. Mennucci, G. A. Petersson, H. Nakatsuji, M. Caricato, X. Li, H. P. Hratchian, A. F. Izmaylov, J. Bloino, G. Zheng, J. L. Sonnenberg, M. Hada, M. Ehara, K. Toyota, R. Fukuda, J. Hasegawa, M. Ishida, T. Nakajima, Y. Honda, O. Kitao, H. Nakai, T. Vreven, J. A. Montgomery, Jr., J. E. Peralta, F. Ogliaro, M. Bearpark, J. J. Heyd, E. Brothers, K. N. Kudin, V. N. Staroverov, R. Kobayashi, J. Normand, K. Raghavachari, A. Rendell, J. C. Burant, S. S. Iyengar, J. Tomasi, M. Cossi, N. Rega, J. M. Millam, M. Klene, J. E. Knox, J. B. Cross, V. Bakken, C. Adamo, J. Jaramillo, R. Gomperts, R. E. Stratmann, O. Yazyev, A. J. Austin, R. Cammi, C. Pomelli, J. W. Ochterski, R. L. Martin, K. Morokuma, V. G. Zakrzewski, G. A. Voth, P. Salvador, J. J. Dannenberg, S. Dapprich, A. D. Daniels, O. Farkas, J. B. Foresman, J. V. Ortiz, J. Cioslowski and D. J. Fox, Gaussian 09, Gaussian, Inc., Wallingford, CT, 2009.

19 A. P. Scott and L. Radom, J. Phys. Chem., 1996, 100, 16502. 20 M. Alcolea Palafox, M. Gil, J. L. Núñez and G. Tardajos, Int. J. Quantum Chem., 2002, 89, 147.

21 (a) D. Pan and D. L. Phillips, J. Phys. Chem. A, 1999, 103, 4737; (b) D. Pan, L. C. T. Shoute and D. L. Phillips, J. Phys. Chem. A, 1999, 103, 6851; (c) H. Jian, J. Xiang, K. Sun, J. Sun, C. Chen, B. Zhou, Y. Liu and G. Xu, J. Colloid Interface Sci., 2000, 229, 212; (d) R. Millen, D. de Faria and M. Temperini, Vib. Spectrosc., 2001, 27, 89.

22 (a) M. Bolboaca, T. Iliescu and W. Kiefer, Chem. Phys., 2004, 298, 87; (b) M. Bolboaca, T. Iliescu, C. Paizs, F. D. Irimie and W. Kiefer, J. Phys. Chem. A, 2003, 107, 1811.

23 N. M. B. Perney, J. J. Baumberg, M. E. Zoorob, M. D. B. Charlton, S. Mahnkopf and C. M. Netti, Opt. Express, 2006, 14, 847.

24 H. Wackerbarth, C. Lenth, S. Funke, L. Gundrum, F. Rotter, F. Büttner, J. Hagemann, M. Wellhausen, U. Plachetka, C. Moormann, M. Strube and A. Walte, Proc. SPIE, 2013, 8896, 889609. 